\title{
Relationship between Biomechanical Characteristics of Spinal Manipulation and Neural Responses in an Animal Model: Effect of Linear Control of Thrust Displacement versus Force, Thrust Amplitude, Thrust Duration, and Thrust Rate
}

\author{
William R. Reed, ${ }^{1}$ Dong-Yuan Cao, ${ }^{1}$ Cynthia R. Long, \\ Gregory N. Kawchuk, ${ }^{2}$ and Joel G. Pickar ${ }^{1}$ \\ ${ }^{1}$ Palmer College of Chiropractic, Palmer Center for Chiropractic Research, Davenport, IA 52803, USA \\ ${ }^{2}$ Department of Physical Therapy, University of Alberta, Edmonton, AB, Canada, T6G 2R3
}

Correspondence should be addressed to Joel G. Pickar; pickar_j@palmer.edu

Received 15 September 2012; Revised 2 December 2012; Accepted 12 December 2012

Academic Editor: Vincenzo De Feo

Copyright (C) 2013 William R. Reed et al. This is an open access article distributed under the Creative Commons Attribution License, which permits unrestricted use, distribution, and reproduction in any medium, provided the original work is properly cited.

\begin{abstract}
High velocity low amplitude spinal manipulation (HVLA-SM) is used frequently to treat musculoskeletal complaints. Little is known about the intervention's biomechanical characteristics that determine its clinical benefit. Using an animal preparation, we determined how neural activity from lumbar muscle spindles during a lumbar HVLA-SM is affected by the type of thrust control and by the thrust's amplitude, duration, and rate. A mechanical device was used to apply a linear increase in thrust displacement or force and to control thrust duration. Under displacement control, neural responses during the HVLA-SM increased in a fashion graded with thrust amplitude. Under force control neural responses were similar regardless of the thrust amplitude. Decreasing thrust durations at all thrust amplitudes except the smallest thrust displacement had an overall significant effect on increasing muscle spindle activity during the HVLA-SMs. Under force control, spindle responses specifically and significantly increased between thrust durations of 75 and $150 \mathrm{~ms}$ suggesting the presence of a threshold value. Thrust velocities greater than $20-30 \mathrm{~mm} / \mathrm{s}$ and thrust rates greater than $300 \mathrm{~N} / \mathrm{s}$ tended to maximize the spindle responses. This study provides a basis for considering biomechanical characteristics of an HVLA-SM that should be measured and reported in clinical efficacy studies to help define effective clinical dosages.
\end{abstract}

\section{Introduction}

Spinal manipulation is a form of manual therapy used frequently to address musculoskeletal complaints. Utilization data [1-3] indicates most patients receive a short lever, high-velocity low-amplitude type of spinal manipulation (HVLA-SM). An HVLA-SM has biomechanical characteristics broadly distinguished by a preload force that initially removes slack from the intervertebral tissues followed by a single thrust delivered quickly (on the order of tenths of a second or less). The thrust is often directed in a specific direction to an anatomical area of a pre-specified vertebra $[4,5]$. A recent systematic review of randomized clinical trials specifically investigating the therapeutic benefit of
HVLA-SM indicates that, despite the wide variability in how clinical outcomes have been measured and reported, HVLASM produces modest yet consistent clinical benefit [6]. The mechanisms of action are elusive.

Like other therapeutic interventions requiring manual deftness, such as surgery, the successful delivery of an HVLASM combines knowledge about the motor skills critical for maximizing clinical success and mastery of those motor skills [7]. These motor skills include learning to control the applied force or displacement during the manipulative thrust. With control of these parameters it is important to know whether it is more effective to control force versus displacement and whether there is a thrust amplitude or range of amplitudes critical to producing favorable clinical outcomes? Similarly, 
is there a specific thrust duration or range of durations over which the peak force or displacement amplitude develops that can make an HVLA-SM most effective? The answers to these questions may be viewed as elements of the manipulation's dosage, conceptually similar to chemical characteristics, such as molecular composition and permeability, which determine a drug's clinically effective dosage.

Evidence-based patient care informed by data from clinical studies requires knowing as precisely as possible the relevant characteristics of treatments used in these studies. To our knowledge, no clinical studies have yet addressed the relationship between an HVLA-SM's biomechanical characteristics and any clinical outcome. While the relationship between the number of HVLA-SM treatments and clinical benefit has been studied $[8,9]$, the manipulation's biomechanical characteristics were neither standardized nor measured. Consequently, how these characteristics might have affected the clinical outcomes is not determinable. Initial animal studies suggest that HVLA-SMs delivered with thrust durations $100 \mathrm{~ms}$ or less substantially increase sensory input from paraspinal proprioceptors $[10,11]$. Thrust duration interacts with thrust amplitude toward changing spinal stiffness in ways that have only begun to be studied [12]. Some but not all neuromuscular responses from paraspinal muscles are graded with both the manipulation's amplitude and duration [13].

Motivated by the idea that our ability to determine an HVLA-SM's clinical efficacy is hampered by our lack of knowledge about the relationship between the intervention's biomechanical characteristics and clinical outcomes, we used an animal preparation to determine the relationship between a simulated HVLA-SM's biomechanical characteristics and changes in neural activity from muscle spindles in lumbar paraspinal muscles. This approach was used because across healthcare professions that use spinal manipulation, spinal manipulation's mechanism of action is thought to be largely mediated by changes in spinal biomechanics and/or changes in sensory input arising from paraspinal tissues [14-17] including muscle spindles in the back muscles [18]. Similar invasive studies could not be performed in humans. The purpose of the study was to determine how the type of thrust control (applied as a linear increase in either force or displacement), the thrust amplitude, thrust duration, and consequent thrust rate of an HVLA-SM affected the pattern or magnitude of neural activity from muscle spindles. Defining the physical characteristics of an HVLA-SM that have the greatest influence on neural activity will help clarify those elements that have the greatest potential to enhance the effectiveness of this intervention.

\section{Methods}

2.1. General Description. Data were obtained from single, peripheral sensory neurons innervating muscle spindles in multifidus or longissimus muscles in a large sample of anesthetized cats $(n=112)$ of either sex weighing an average of $3.97 \mathrm{~kg}$ (SD 0.85). All experiments were reviewed for ethical considerations and approved by Palmer College of Chiropractic Institutional Animal Care and Use
Committee (no. 20070101). HVLA-SMs were delivered using a programmable, computer-controlled mechanical device enabling us to systematically control the manipulation's biomechanical characteristics. HVLA-SMs were considered to simulate a clinically delivered manipulation based upon using a range of thrust amplitudes and durations similar to those reported in the clinical literature (see Sections 2.6 and 2.7). Each HVLA-SM was applied to the cutaneous tissues overlying the $\mathrm{L}_{6}$ vertebra (cats have 7 vertebrae) while simultaneously recording neural action potentials from muscle spindles innervated by the $\mathrm{L}_{6}$ spinal nerve. The frequency of action potentials was determined before and during the delivery of each HVLA-SM.

Responses from only one neuron could be investigated per cat because, following the series of HVLA-SMs, cutaneous tissues overlying the $\mathrm{L}_{6}$ vertebra were cut to expose deeper back tissues in order to confirm that the neuron innervated a muscle spindle in the lumbar multifidus or longissimus muscle. No responses to HVLA-SM were studied once the cutaneous tissues overlying the $\mathrm{L}_{6}$ vertebra were cut. Calibrated nylon monofilaments (Stoelting, IL, USA) were applied to the exposed back muscles to verify the location of the most sensitive portion of the back from which the neuron could be activated (i.e., the neuron's receptive field). Sensory neurons were identified as muscle spindle neurons based upon standard neurophysiological techniques including their increased discharge to succinylcholine $(100-400 \mathrm{mg} / \mathrm{kg}$ intraarterially (ia)) and decreased discharge to electrically induced muscle contraction as described previously [19]. In addition, to help differentiate muscle spindle from Golgi Tendon Organ responses, we determined whether the neuron was able to produce a sustained response to a fast vibratory stimulus applied to the muscle's surface close to the neuron's receptive field [20].

2.2. General Surgery. Surgical procedures have been presented previously $[19,21,22]$ and are also described here. Anesthesia was induced using a mixture of $\mathrm{O}_{2}$ and isoflurane, first delivered to a sealed plastic chamber $(5 \mathrm{~L} / \mathrm{min}$ and $5 \%$, resp.), and then through a facemask $(2 \mathrm{~L} / \mathrm{min}$ and $2 \%)$. After placing catheters in a common carotid artery and an external jugular vein to monitor blood pressure and introduce fluids, respectively, and after intubating the trachea to mechanically ventilate the lungs, deep anesthesia was maintained with Nembutal ( $35 \mathrm{mg} / \mathrm{kg}$ intravenously (iv)). Additional doses $(5 \mathrm{mg} / \mathrm{kg}$, iv) were administered when the cat demonstrated a withdrawal reflex to noxious pinching of the toe pad, or when mean arterial pressure either increased spontaneously above $120 \mathrm{mmHg}$ or in response to surgical manipulation. Arterial $\mathrm{pH}, \mathrm{PCO}_{2}$, and $\mathrm{PO}_{2}$ were regularly monitored throughout the experiment using an i-Stat $\mathrm{pH} /$ blood gas analyzer (i-Stat Corp., East Windsor, NJ, USA) and maintained within the normal range ( $\mathrm{pH} 7.32$ to $7.43 ; \mathrm{PCO}_{2}, 32-37 \mathrm{mmHg} ; \mathrm{PO}_{2}$, $>85 \mathrm{mmHg}$ ).

2.3. Spinal Surgery and Nerve Preparation. Studying the effects of a spinal manipulation on responses from peripheral sensory neurons innervating the manipulated back tissues 


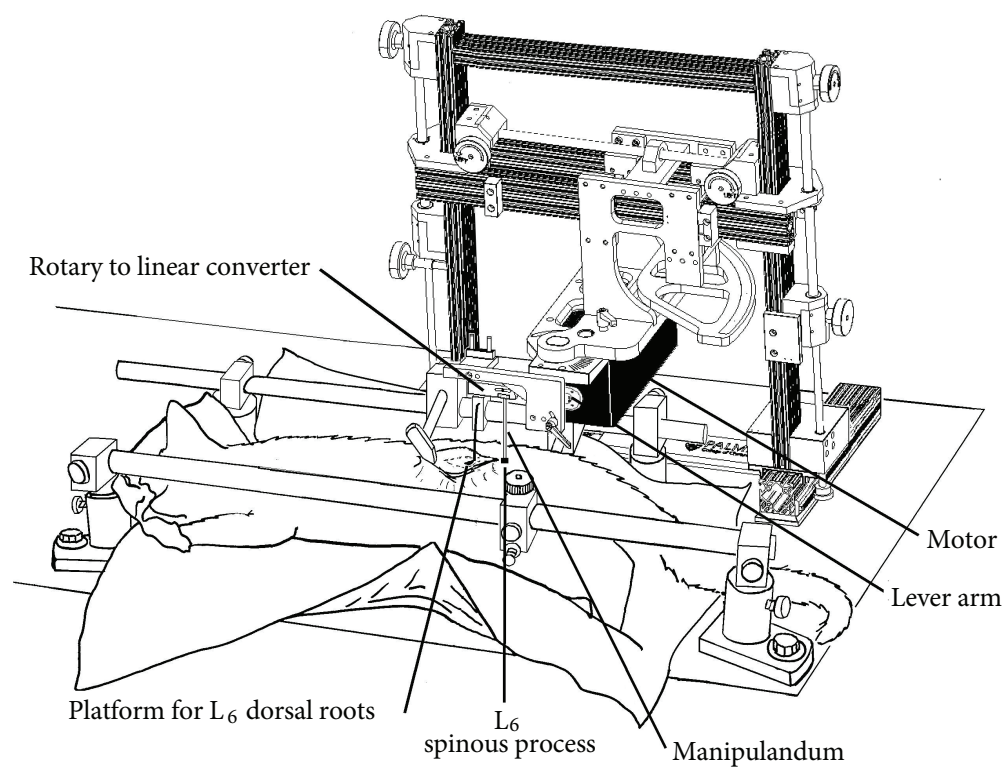

Figure 1: Schematic of the experimental set-up showing exposure of the $\mathrm{L}_{6}$ dorsal roots, the intact lower lumbar spine, and the device used to control delivery of the spinal manipulations at the $\mathrm{L}_{6}$ spinous process.

is problematic because access to the nervous system is limited $[19,23]$. Peripheral nerves innervating lumbar spinal tissues are not lengthy and substantial removal of the dorsal musculature appears necessary for accessing neural recording sites in the dorsal roots. We have previously developed [19] an in vivo cat preparation and have now improved upon it by keeping the skin and deep paraspinal tissues intact bilaterally from the $\mathrm{L}_{6}$ vertebra caudalwards where the HVLA-SM is delivered. The $\mathrm{L}_{6}$ lumbar dorsal roots are sufficiently exposed for electrophysiological recordings. The experimental setup is shown in Figure 1.

Exposing the $\mathrm{L}_{6}$ dorsal roots and keeping the lower lumbar spine intact takes advantage of the anatomical fact that the caudal most rootlets of $\mathrm{L}_{6}$ enter the spinal cord approximately two vertebral segments $(30-35 \mathrm{~mm})$ rostral to the $\mathrm{L}_{6}$ spinal nerve's entry through the $\mathrm{L}_{6}$ intervertebral foramina. Only the skin over the $\mathrm{L}_{4}$ and $\mathrm{L}_{5}$ vertebra was incised and the lumbodorsal fascia opened only from $L_{4}$ to $L_{5}$. Multifidus, longissimus, and lumbococcygeus muscles over only the $\mathrm{L}_{4}$ and $\mathrm{L}_{5}$ vertebrae on the left side were removed. The laminae of the $\mathrm{L}_{5}$ vertebra and of the caudal half of the $\mathrm{L}_{4}$ vertebra were removed to expose the cranial portion of the $\mathrm{L}_{6}$ dorsal rootlets. The lumbar spine was anchored at $\mathrm{L}_{4}$ and the pelvis by fixing the $\mathrm{L}_{4}$ spinous process and the iliac crests in a Kopf spinal unit (Figure 1). The paraspinal tissues were bathed in warm mineral oil $\left(37^{\circ} \mathrm{C}\right)$ to prevent desiccation. With the dorsal roots exposed and placed on a glass platform (Figure 1), thin filaments from the rootlets were teased using forceps under a dissecting microscope until action potentials from a single neuron were identified. The action potentials were recorded using a PC based data acquisition system (Spike 2, Cambridge Electronic Design, UK).

2.4. Delivery of HVLA-SM. Components of the mechanical device that delivered and systematically controlled the manipulation's biomechanical characteristics are shown schematically in Figure 1. The device was comprised of an electronic feedback control system, a motor, and a lever arm attached to the motor's shaft (Aurora Scientific, Lever System Model 310). Computer-controlled rotation of the motor's shaft rotated the lever arm. The lever arm was attached to a custom built rotary-to-linear converter which in turn was attached to a manipulandum (see Figure 1) that contacted the back of the cat. The rotary-to-linear converter consisted of a polycarbonate block machined with a narrow slot that received the end of the motor's lever arm and held two parallel guide posts passing through linear bearings in an adjacent fixed bearing block. The manipulandum consisted of a thin titanium rod $(0.2 \mathrm{~cm}$ diameter $\times 12 \mathrm{~cm}$ long $)$ secured at one end into the rotary-to-linear converter and inserted at the other end into a small plexiglass tip. The tip made direct contact with skin overlying the $\mathrm{L}_{6}$ spinous process. The converter transformed the lever arm's rotary motion to linear motion of the manipulandum.

With the cat lying prone, HVLA-SMs were applied at the $\mathrm{L}_{6}$ spinous process in a vertical direction, that is, toward ventralward from the back of the cat. The electronic feedback control system allowed the motor to control either the force applied at the end of the lever arm (force control) or the distance traveled by the end of the lever arm (displacement control). The manipulandum was always positioned perpendicular to the lever arm so that force and displacement at the end of the lever arm were the same as at the back of the cat where it was contacted by the tip of the manipulandum. Forces and displacements during the HVLA-SM were simultaneously measured at outputs from the control system.

The mechanical profile (amplitude versus time) of a clinically delivered HVLA-SM can be roughly represented by the shape of an up-side down letter "V" [24-26]. The HVLASM's thrust phase is represented by the ascending arm of 


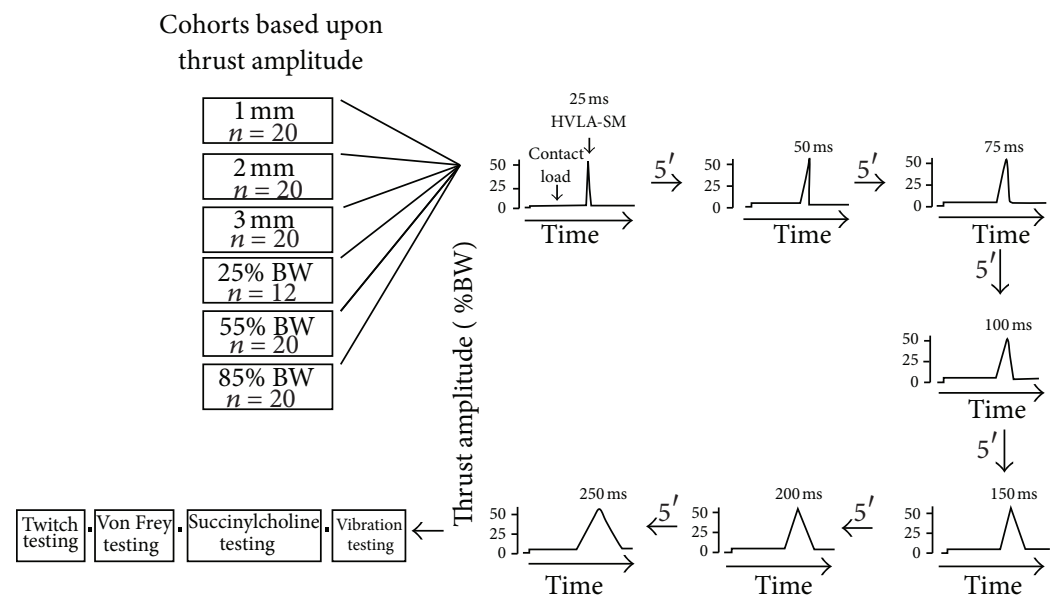

FIGURE 2: Schematic showing the experimental protocols. The protocol for a cat in the 55\% body weight (BW) cohort is depicted. Contact load applied prior to the HVLA-SM removed slack from the soft tissues and engaged the $\mathrm{L}_{6}$ vertebra. The high-velocity low-amplitude spinal manipulations (HVLA-SM) were applied at the spinous process of the $\mathrm{L}_{6}$ vertebra. The 7 thrust durations were presented in random order. Duration of the contact load not drawn to scale. BW: body weight.

the " $\Lambda$ " (see HVLA-SMs in Figure 2). As shown in Figure 2, the vertical height represents thrust amplitude (measured as applied force or displacement) and its horizontal length represents thrust duration (measured in milliseconds). Reaching the thrust amplitude was always controlled linearly that is, in force control the manipulative force increased at a constant rate, and in displacement control the manipulative displacement increased at a constant velocity.

An important goal with the experimental setup was to have physical contact between the cat's back and the manipulandum be similar to the physical contact between a clinician's hand and the lumbar spine of a patient. One way we did this was to have the manipulandum's tip make direct contact with the intact skin overlying the $\mathrm{L}_{6}$ spinous process as previously described. This improved upon earlier studies where the skin had been cut and toothed forceps clamped directly onto the spinous process $[10,11]$. The second way was to customize the manipulandum's plexiglass tip by scaling its contact area with the skin to that used clinically in the lumbar spine. In the human, peak thrust forces are distributed over a relatively circular area between 350 and $1480 \mathrm{~mm}^{2}$ [27] when the pisiform bone is used to apply an HVLA-SM. We scaled this area but not its shape to the cat using a ratio of heights (from caudal to cranial tip of the articular processes) between the cat and human lumbar vertebra. We took direct measurements from cat and human lumbar specimens. The cat $\mathrm{L}_{6}$ vertebra is $23 \mathrm{~mm}$ in height and the comparable human vertebra $\left(\mathrm{L}_{4}\right)$ is $43 \mathrm{~mm}$. The 0.53 ratio was slightly reduced to 0.45 . The final scaled surface area was $70 \mathrm{~mm}^{2}$. The tip's shape was rectangular $(7 \mathrm{~mm} \times 10 \mathrm{~mm})$ with a narrow channel ( $5 \mathrm{~mm}$ wide $\times 2 \mathrm{~mm}$ deep) designed to cradle the sides of the spinous process and help prevent lateral slippage during the HVLA-SM.

2.5. Initial Contact Load. Clinically, the thrust of an HVLA$\mathrm{SM}$ is intended to impart movement to a vertebra [4]. To ensure that vertebral movement could occur at the start of the thrust, we developed a method to identify the applied force which engaged the soft tissues and beyond which the $\mathrm{L}_{6}$ vertebra would be expected to move ventralward (contact load). In each cat, the manipulandum was placed over the $\mathrm{L}_{6}$ spinous process and slowly lowered in displacement control $(1.33 \mathrm{~mm} / \mathrm{s})$, translating the contact point $4 \mathrm{~mm}$ ventralward. We recorded the displacement and the force required to achieve the displacement and plotted them as a force-displacement (F-D) curve. A regression line was fit to the curve's toe region. The force at which the F-D curve diverged from the regression line was considered the contact load reasoning that the level of force at the beginning of this stiffer region represented compression of and/or slack removal from adjacent soft tissues and engagement of vertebral movement. In 19 cats, we visually confirmed that movement had occurred with this contact load. This was accomplished by attaching a vertical post to the cranial edge of the $\mathrm{L}_{6}$ spinous process and capturing the physical movement using a high resolution optical recording system (Motion Pro Digital Image System, Redlake MASD Inc, CA, USA). Video capture was time synched with data acquisition of force and displacement. The force at which movement occurred was compared with the force at which divergence occurred. On average, physical movement of the vertebra began before contact load was attained on the F-D curve (60.8 (SD 14.9) gm versus 64.3 (12.7) gm, resp.).

2.6. Deciding upon Thrust Amplitudes. Choosing clinically relevant thrust amplitudes to use experimentally in an animal model is not straightforward. Clinical effects of spinal manipulation have been investigated in horses $[13,28]$ but the amplitudes used were not been reported. Human clinical studies have measured applied thrust forces but have not provided decision principles that guide the clinician's behavior. The range of forces used for treating the lumbosacral region is reported at $220-550 \mathrm{~N}[24,29]$. Whether this range 
reflects random variation around a mean value or a clinician's intuitive scaling factor is unknown. Nonetheless, we have standardized these forces based upon body weight (BW) assuming an average human BW of $70 \mathrm{~kg}$. This yielded thrust forces in the lumbosacral region that ranged from $31 \%$ to $78 \%$ BW. We used 3 thrust forces $(25 \%, 55 \%$, and $85 \%)$ which encompassed the range used in humans.

Choosing a range of thrust displacements is not straightforward either. In the human cadaveric lumbar spine, Ianuzzi and Khalsa [30] simulated a side posture HVLA-SM using force-time characteristics described above. The manipulated vertebra translated approximately $1.5 \pm 0.5 \mathrm{~mm}$ and rotated $2-3.5 \pm 1.0^{\circ}$ in the direction of the applied force. Nathan and Keller [31] measured intervertebral lumbar motion using pins inserted into human lumbar spinous processes using a mechanical adjusting device (Activator Adjusting Instrument ${ }^{\odot}$ [32]). This device delivers a force-time profile lower in amplitude $(53 \mathrm{~N})$, shorter in duration $(17 \mathrm{~ms})$, but with a faster force rate $(3100 \mathrm{~N} / \mathrm{s})$ compared with a manually applied HVLA-SM. Using the device to deliver a spinal manipulation at the $\mathrm{L}_{2}$ spinous process produced $1.62 \pm$ $1.06 \mathrm{~mm}$ peak axial displacements (in the longitudinal plane), $0.48 \pm 0.1 \mathrm{~mm}$ shear displacements (in the transverse plane), and $0.89 \pm 0.49^{\circ}$ rotations between $\mathrm{L}_{3}$ and $\mathrm{L}_{4}$. Smith et al. [33] found that manipulations given with the device also evoked similar vertebral displacements in the lumbar spine of the dog. $\mathrm{L}_{2}$ translated $0.71 \pm 0.03 \mathrm{~mm}$ and rotated $0.53 \pm 0.15^{\circ}$ on $\mathrm{L}_{3}$ with impulse loads of $53 \mathrm{~N}$. Taken together, these data suggest that relative vertebral displacements are more than $0.5 \mathrm{~mm}$ but less than $2 \mathrm{~mm}$. We used thrust displacements (1, 2 , and $3 \mathrm{~mm}$ ) that included and were slightly higher than this range.

2.7. Deciding upon Thrust Durations. A range of thrust durations that might be clinically relevant were used. In the cervical spine, the time to peak thrust amplitude ranges from 30 to $65 \mathrm{~ms}$ [34]. For HVLA-SM applied to the thoracic and lumbar regions, the thrust phase rises to a peak load in less than $150 \mathrm{~ms}$ [24-26]. We used a wide range of thrust durations $(25,50,75,100,150,200$, and $250 \mathrm{~ms})$ which encompassed those used clinically.

2.8. Experimental Design. The 112 cats were divided into 6 groups. Each group was considered a cohort because its members received the same controlled thrust magnitude. Cohorts were named according to the thrust magnitude they received $(1 \mathrm{~mm}, 2 \mathrm{~mm}, 3 \mathrm{~mm}, 25 \% \mathrm{BW}, 55 \% \mathrm{BW}$, and $85 \%$ BW cohorts). Each cat received the 7 thrust durations $(25,50$, $75,100,150,200$, and $250 \mathrm{~ms})$. The 7 HVLA-SMs were each separated by 5 minutes.

Figure 2 is a schematic showing the experimental protocols. With the device programmed to deliver the desired thrust amplitude, contact load was applied for $30 \mathrm{~s}$ followed by an HVLA-SM with a $25 \mathrm{~ms}$ thrust duration. Five minutes later contact load was again applied followed by a $50 \mathrm{~ms}$ thrust duration and so on. The 7 thrust durations were presented in random order yielding a randomized complete block experimental design.
2.9. Data Management. Neural activity arising from manipulation-induced activation of the muscle spindle was determined by comparing activity during $2 \mathrm{~s}$ immediately preceding each HVLA-SM (baseline) with that during the thrust phase of the HVLA-SM. All neural activity was first quantified as instantaneous frequency (IF) by taking the reciprocal of the time interval between successive action potentials. Mean IF (MIF) was calculated for baseline and the thrust phase. The change in MIF ( $\triangle \mathrm{MIF}$ ) due to the HVLA-SM was the response measure. It was calculated by subtracting MIF during baseline from MIF during the thrust phase. All neural activity is reported in impulses per sec (imp/s).

Muscle spindle neurons can have a brief, very high frequency burst of activity at the beginning of muscle movement when the spindle apparatus begins to stretch. This activity represents a response to the movement's acceleration [35]. We were interested in the spindle's response during the constant rate of thrust. Therefore MIF calculated during thrust phase did not include the first $12.5 \mathrm{~ms}$ which provided adequate conduction time to ensure that action potentials due to the acceleration were not included in the calculation.

2.10. Statistical Analysis. Sample size calculations were obtained by estimating standard deviations from two previous studies $[10,11]$ in which thrust amplitudes were standardized based upon body weight and displacement. Standard deviations varied between 62 and $67 \mathrm{imp} / \mathrm{s}$. Assuming similar patterns of activity would be seen as in these previous studies cohort sizes of 20 cats would yield $>99 \%$ power for the overall $F$-test and at least $80 \%$ power to detect mean differences of $60 \mathrm{imp} / \mathrm{s}$ or more between adjacent levels of thrust duration. Thus all cohorts consisted of 20 cats except the $25 \%$ BW cohort. This was the last cohort studied. With data analyses already completed for the $55 \%$ BW and $85 \%$ BW cohorts, we saw little difference in mean $\triangle$ MIF between either of these cohorts and the 25\% BW cohort (as seen in Figure 4). It was deemed appropriate to reduce the number of cats.

Neural responses were compared across the 7 levels of thrust duration $(25,50,75,100,150,200,250 \mathrm{~ms})$ using a one-way ANOVA for the randomized complete block design. Each cat served as a blocking factor in order to control for the relative levels of spindle activity and intra-animal variability. An overall $F$-test was used to test whether the means were the same over the thrust durations. For statistically significant overall $F$-tests, only 6 preplanned contrasts between mean $\triangle$ MIFs at adjacent durations were compared to detect the possibility of a threshold effect. Overall $F$-tests and preplanned contrasts were tested at the 0.05 level. Data are reported as means and 95\% confidence intervals (lower, upper $95 \% \mathrm{CI}$ ) unless otherwise noted.

\section{Results}

3.1. Neuronal Classification. One hundred twelve lumbar paraspinal muscle spindle neurons were studied in the 6 cohorts. Table 1 shows the distribution of classification characteristics and responses among the 6 cohorts. Each neuron's 
TABLE 1: Distribution of classification characteristics.

\begin{tabular}{|c|c|c|c|c|c|c|c|c|}
\hline & \multirow{2}{*}{ Muscle } & \multicolumn{7}{|c|}{ COHORT (based upon thrust amplitude) } \\
\hline & & $1 \mathrm{~mm}$ & $2 \mathrm{~mm}$ & $3 \mathrm{~mm}$ & $25 \%$ BW & $55 \% \mathrm{BW}$ & $85 \% \mathrm{BW}$ & Total \\
\hline Body weight mean $(N)(\mathrm{SD})$ & & $38.3(5.5)$ & $39.1(8.4)$ & $39.2(9.2)$ & $47.5(9.2)$ & $40.6(6.9)$ & $32.0(5.3)$ & $38.9(8.3)$ \\
\hline \multirow{2}{*}{ Receptive field location $(n)$} & \multirow{2}{*}{$\begin{array}{l}\text { Long. } \\
\text { Multifidus }\end{array}$} & 16 & 17 & 15 & 9 & 16 & 19 & 92 \\
\hline & & 3 & 3 & 5 & 3 & 4 & 1 & 19 \\
\hline Tested \& responded to succinylcholine $(n)$ & & 20 & 20 & 20 & 12 & 20 & 20 & 112 \\
\hline Tested \& responded to vibration $(n)$ & & 15 & 19 & 20 & 11 & 19 & 20 & 104 \\
\hline Tested \& responded to twitch $(n)$ & & 14 & 19 & 19 & 11 & 19 & 18 & 99 \\
\hline
\end{tabular}

Long.: Longissimus; N: Newtons, SD: standard deviation, BW: body weight, $n$ : number of occurrences.

receptive field was localized to either the longissimus or multifidus muscles except for one neuron in the $1 \mathrm{~mm}$ cohort whose neural activity was lost before its receptive field could be localized to a specific back muscle. Lumbar longissimus muscle contained the receptive fields of 92 neurons. In this muscle, the most sensitive portion of each neuron's receptive field was most often located at the level of the $\mathrm{L}_{6-7}$ facet joint (34\%) or the $\mathrm{L}_{7}$ spinous process (31\%). The most sensitive portion of the remaining fields in the longissimus muscle were at the level of the $\mathrm{L}_{6}$ spinous process (17\%), between the $\mathrm{L}_{6}$ and $\mathrm{L}_{7}$ spinous (8\%), or at the level of the $\mathrm{L}_{7}-\mathrm{S}_{1}$ facet joint (10\%). The lumbar multifidus muscle contained the receptive fields of the remaining 19 neurons. In the multifidus muscle, the most sensitive portion each receptive field was located most often at the level of $\mathrm{L}_{7}-\mathrm{S}_{1}$ facet joint $(47 \%)$ or at the level of $\mathrm{L}_{7}$ spinous process (32\%). The remaining fields were located at the level of the $\mathrm{L}_{6}$ spinous process $(11 \%)$, in the multifidus between the $\mathrm{L}_{6}$ and $\mathrm{L}_{7}$ spinous (5\%) or at the level of the $\mathrm{L}_{6-7}$ facet joint $(5 \%)$.

Succinylcholine injection (ia) induced a relatively high frequency and long-lasting discharge in all 112 neurons. On average, mean maximal instantaneous discharge frequency following injection reached $57 \mathrm{imp} / \mathrm{s}$ above baseline (range: $3.3-175.9 \mathrm{imp} / \mathrm{s}$ ) and remained above baseline for at least $40 \mathrm{~s}$. The increase in discharge began within $15 \mathrm{~s}$ of injection on average (range 2.7 to $53.5 \mathrm{~s}$ ) and became maximal within $55 \mathrm{~s}$ (range 6.3-183.4s). Nearly all neurons $(n=101)$ responded to a single bolus injection of succinylcholine $(100 \mathrm{ug} / \mathrm{kg}$, ia). Eleven neurons responded following a second bolus injection. The spindle with the smallest response to succinylcholine $(3.3 \mathrm{imp} / \mathrm{s})$ had limited vascular accessibility in that the direct depolarizing effect of $0.2 \mathrm{~mL}$ potassium chloride (1000-fold dilution from a saturated solution) injected intra-arterially increased blood pressure but did not further increase spindle discharge. All neurons tested with vibration $(n=104)$ produced a sustained response to the vibratory stimulus. All neurons tested with bipolar muscle stimulation (amplitude: 0.1-0.3 mA; duration: $50 \mu \mathrm{s}, n=99$ ) were silenced by it.

\subsection{Responses to Delivery of the HVLA-SM under Displacement Control}

3.2.1. Effect of Varying Amplitude of Thrust Displacement. As thrust displacement was increased the magnitude of lumbar

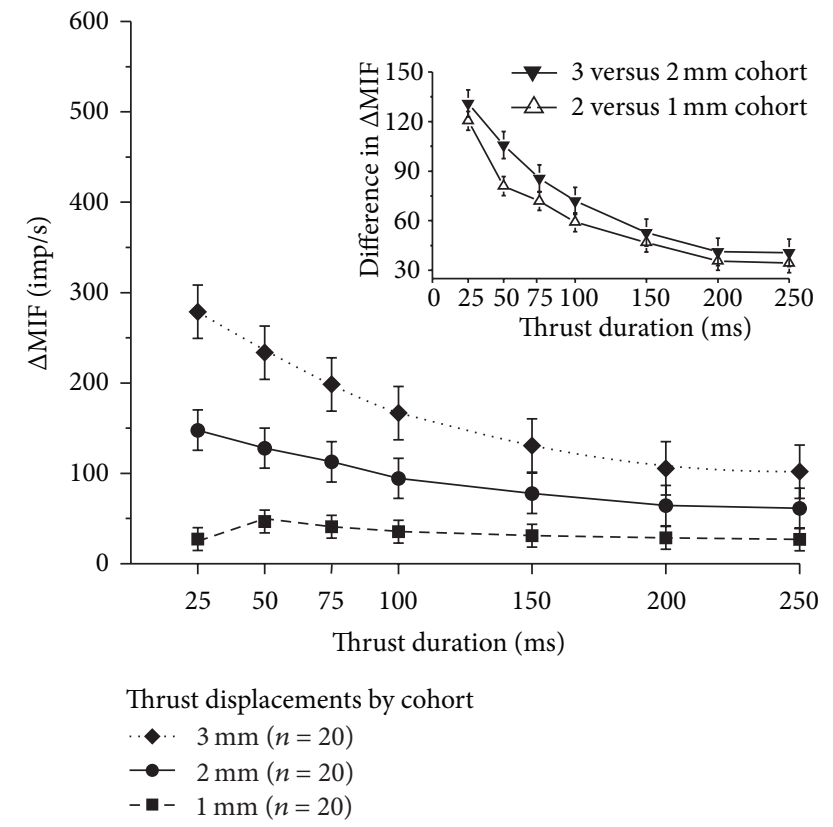

FIGURE 3: Average change in spindle discharge to 3 thrust displacements and 7 thrust durations applied under displacement control. The inset shows that lumbar muscle spindles responded more as thrust displacement increased from 2 to $3 \mathrm{~mm}$ than as it increased from 1 to $2 \mathrm{~mm}$. Symbols represent average for the cohort. Error bars represent adjusted $95 \%$ confidence intervals. $\triangle \mathrm{MIF}$ change in mean instantaneous frequency, imp/s = number of impulses per second. $n=$ number of cats in the cohort.

muscle spindle discharge increased (Figure 3). The increases occurred at nearly every thrust duration indicated by the nonoverlapping $95 \%$ confidence intervals. Lumbar muscle spindles responded more as thrust displacement increased from 2 to $3 \mathrm{~mm}$ than as it increased from 1 to $2 \mathrm{~mm}$ because muscle spindle discharge was consistently higher at each thrust duration (inset in Figure 3).

3.2.2. Effect of Varying Thrust Duration. The magnitude of thrust duration shown in Figure 3 significantly affected muscle spindle discharge for thrust amplitudes of $2 \mathrm{~mm}$ $\left(F_{6,114}=8.62, P<0.001\right)$ and $3 \mathrm{~mm}\left(F_{6,114}=20.22, P<\right.$ $0.001)$ but not $1 \mathrm{~mm}\left(F_{6,114}=1.41, P=0.22\right)$. A pattern is clearly evident where shorter thrust durations caused graded 


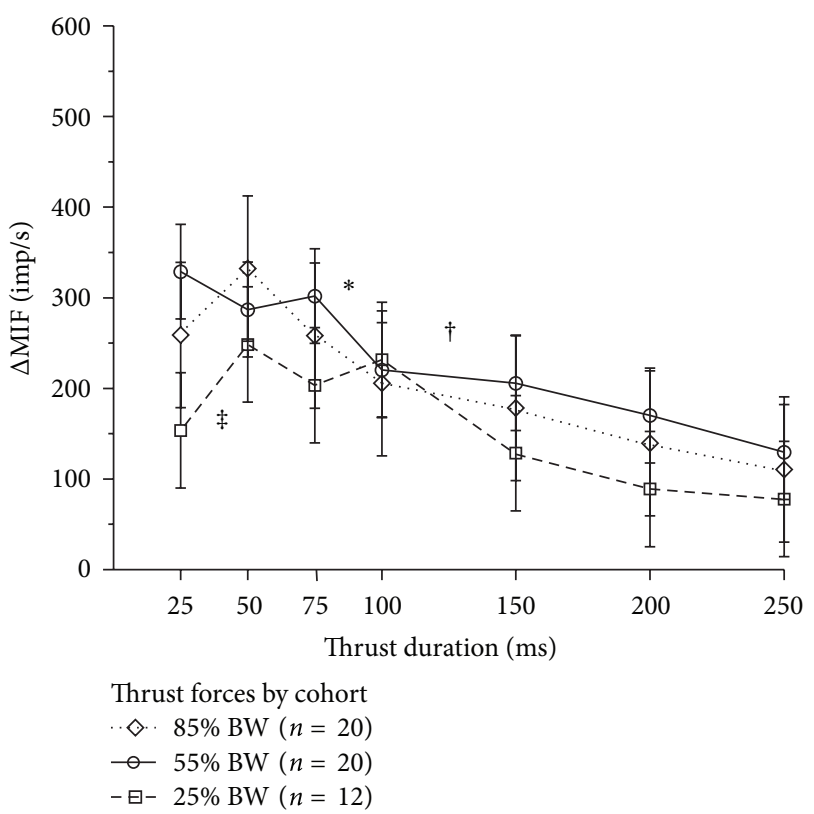

FIgURE 4: Average change in mean spindle discharge to spinal manipulation delivered under force control as thrust duration becomes shorter, thrust amplitude becomes larger. Thrust amplitude based upon each cat's body weight. Symbols represent average for the cohort. Error bars represent adjusted 95\% confidence intervals. ${ }^{\ddagger} P=0.04$ between 25 and 50 ms thrust duration for $25 \%$ BW. ${ }^{\dagger} P=0.03$ between 150 and $100 \mathrm{~ms}$ thrust duration for $25 \%$ BW. ${ }^{*} P=0.03$ between 100 and 75 ms thrust duration for $55 \%$ BW. Abbreviations identical to those in Figure 3.

increases in spindle discharge. However, a priori planned comparisons between contiguous thrust durations for the 2 and $3 \mathrm{~mm}$ peak thrust displacements showed that none of the increases were statistically significant suggesting there was no clear threshold value for thrust duration at which the HVLASM could be considered to have increased muscle spindle discharge significantly. Between the longest thrust durations of 200 and $250 \mathrm{~ms}$ at both the 2 and $3 \mathrm{~mm}$ thrust amplitudes, the change in muscle spindle discharge increased very little. However, as thrust duration became shorter than $200 \mathrm{~ms}$, muscle spindle discharge increased. The steepest increase occurred when thrust duration became $100 \mathrm{~ms}$ or shorter. For the $3 \mathrm{~mm}$ thrust amplitude at thrust durations $100 \mathrm{~ms}$ or shorter, mean spindle discharge was generally higher than $200 \mathrm{imp} / \mathrm{s}$, but below $200 \mathrm{imp} / \mathrm{s}$ for both the 1 and $2 \mathrm{~mm}$ thrust amplitudes.

\subsection{Responses to Delivery of the HVLA-SM under Force Control}

3.3.1. Effect of Varying Amplitude of Thrust Force. In contrast to controlling and varying the amplitude of thrust displacement, controlling and varying the amplitude of thrust force did not clearly produce graded increases in muscle spindle discharge (Figure 4). There was substantial overlap between the $95 \%$ confidence intervals across the three thrust forces. A $55 \%$ BW thrust force could increase mean spindle discharge more than the lower $(25 \% \mathrm{BW})$ as well as the higher $(85 \%$

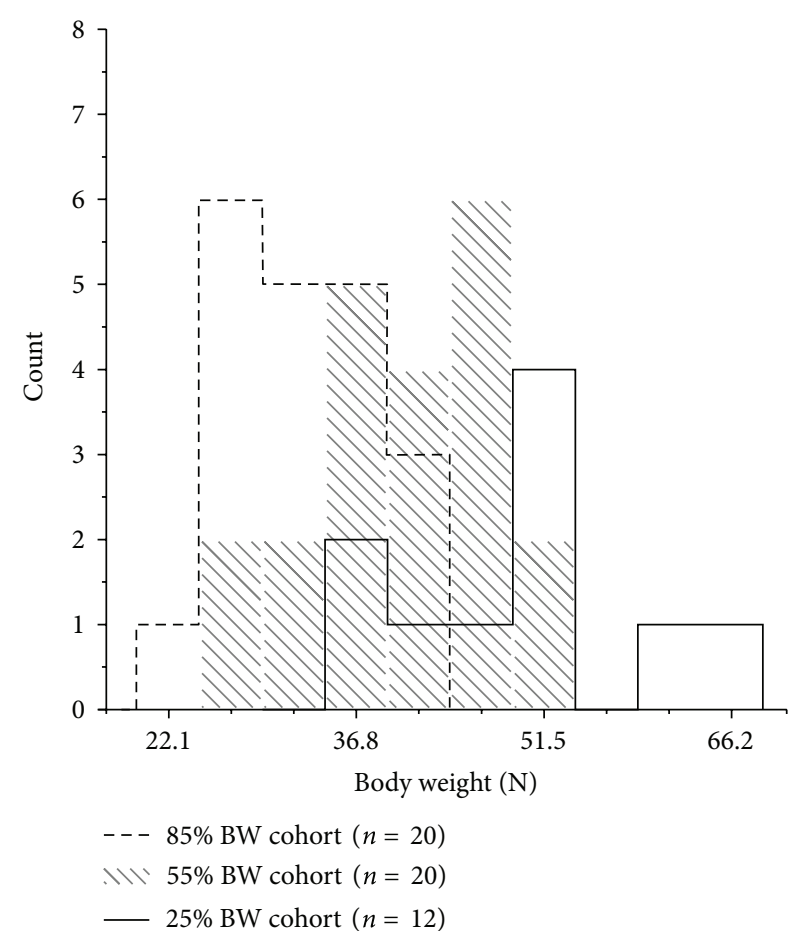

FIGURE 5: Distribution of body weights in the 3 cohorts receiving an HVLA-SM where peak thrust force was controlled. $\mathrm{N}=$ Newtons.

BW) thrust force. However, it was important to recognize the possibility that some cats in the $85 \%$ BW cohort may not have received an actual thrust force (measured in Newtons) much greater than cats in either the $55 \%$ BW or $25 \%$ BW cohorts because the actual thrust force used in each of these cohorts was relative to each cat's own body weight. This is suggested in Table 1 by the fact that the mean body weight in the $85 \%$ BW cohort $(32.0 \mathrm{~N})$ was less than the mean body weight in the $25 \%$ BW cohort $(47.5 \mathrm{~N})$. Figure 5 confirms this possibility because the distribution of body weights for the $85 \%$ BW cohort is shifted toward the left compared to the 55\% BW cohort and to the right for the 25\% BW cohort. For example, the cat weighing $22.1 \mathrm{~N}$ in the $85 \% \mathrm{BW}$ cohort received a thrust force of $18.8 \mathrm{~N}$ similar to the $16.7 \mathrm{~N}$ thrust force received by the cat weighing $66.6 \mathrm{~N}$ in the $25 \% \mathrm{BW}$ cohort.

Consequently, to completely determine the effect of varying thrust duration under force control, we reorganized the data from the 52 cats in the three \%BW cohorts. The reorganization was based upon the actual thrust force each cat received and the average body weight $(38.9 \mathrm{~N})$ of the 52 cats $(\mathrm{ABW})$. Actual thrust force was expressed as a percentage of $\mathrm{ABW}(\% \mathrm{ABW})$. The reorganization yielded 3 groups where thrust force was centered around $25 \%, 55 \%$, or $85 \% \pm 15 \%$ ABW. The $25 \pm 15 \% \mathrm{ABW}$ group received a mean thrust force of $12.1 \mathrm{~N}$ (range: $9.7 \mathrm{~N}$ to 15.2 ), the $55 \% \pm 15 \% \mathrm{ABW}$ group received a mean thrust force of $22.2 \mathrm{~N}$ (range: 16.0 to 26.7 ), and the $85 \% \pm 15 \% \mathrm{ABW}$ group received a mean thrust force of $30.6 \mathrm{~N}$ (range: 27.6 to $36.3 \mathrm{~N}$ ). The effects of varying thrust duration based upon relative thrust force $(25 \%, 55 \%$, and $85 \%$ BW cohorts) and the absolute range of thrust forces 


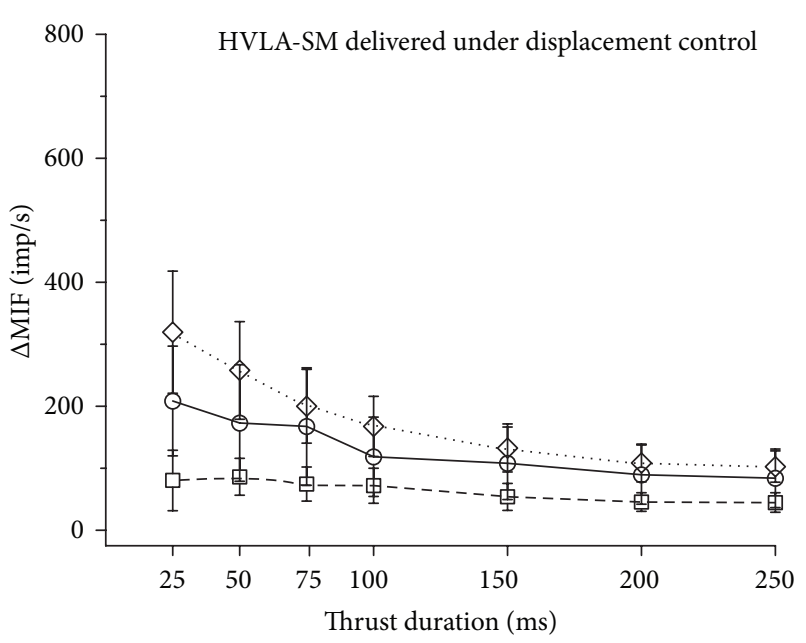

Peak thrust force

•. $60-85 \% \mathrm{BW}(n=9)$

- $30-55 \% \mathrm{BW}(n=13)$

$-\boxminus-\leq 25 \% \mathrm{BW}(n=34)$

(a)

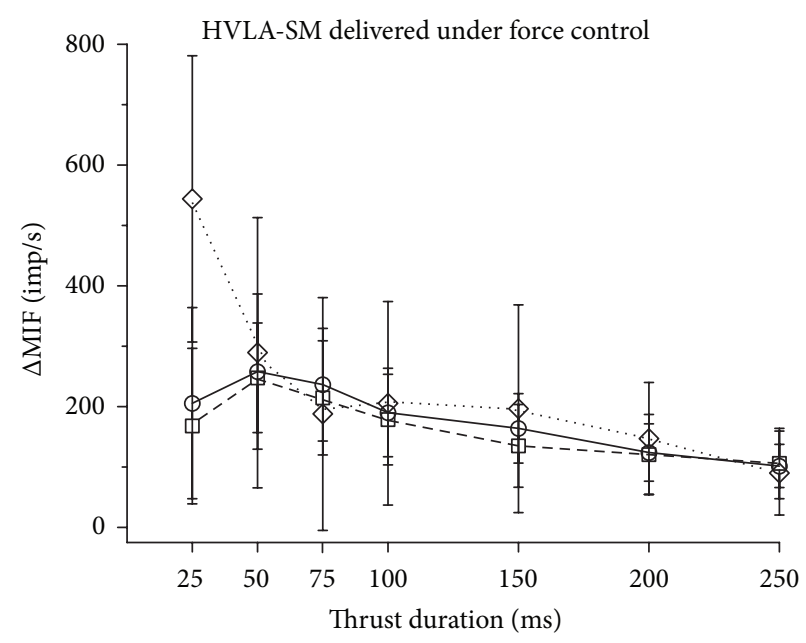

Peak thrust displacement
$\diamond \quad 3.5-4.5 \mathrm{~mm}(n=6)$
$\odot->2.5$ and $<3.5 \mathrm{~mm}(n=13)$
$-\boxminus-1.5-2.5 \mathrm{~mm}(n=15)$

(b)

Figure 6: Regrouping of data shown in Figures 3 and 4 based upon (a) 3 ranges of thrust force that developed during displacement control of the HVLA-SM's delivery and (b) 3 ranges of thrust displacement that developed during force control of the HVLA-SM's. Symbols represent average for the cohort. Error bars represent adjusted 95\% confidence intervals. Abbreviations identical to those in Figure 3.

$(25 \%, 55 \%$, or $85 \% \pm 15 \%$ ABW reorganized groupings) are presented in the next subsection.

3.3.2. Effect of Varying Thrust Duration. Thrust duration significantly affected muscle spindle discharge at all three thrust forces in the cohorts $\left(25 \%\right.$ BW: $F_{6,66}=4.53, P<$ $0.001,55 \%$ BW: $F_{6,114}=7.75, P<0.001$; and $85 \%$ BW, $\left.F_{6,114}=3.62, P=0.003\right)$. Pre-planned comparisons between contiguous thrust durations suggest the presence of threshold values of thrust duration for increasing muscle spindle discharge. Significantly greater increases in muscle spindle discharge occurred between the 150 and $100 \mathrm{~ms}$ durations at a thrust force of $25 \% \mathrm{BW}\left({ }^{\dagger} P=0.03\right.$, in Figure 4) and between 100 and $75 \mathrm{~ms}$ at a thrust force of $55 \% \mathrm{BW}\left({ }^{*} \mathrm{P}=\right.$ 0.03 , in Figure 4$)$. With a thrust force of $25 \% \mathrm{BW}$, spindle discharge during the $25 \mathrm{~ms}$ thrust duration was significantly less than during the $50 \mathrm{~ms}$ thrust duration ${ }^{\ddagger} P=0.04$, in Figure 4).

Similarly, thrust duration significantly affected muscle spindle discharge in all 3 groups reorganized based upon $\%$ ABW $\left(25 \% \pm 15 \%\right.$ ABW: $F_{6,66}=3.77, P=0.003 ; 55 \% \pm 15 \%$ ABW: $F_{6,144}=9.46, P<0.001$; and $85 \% \pm 15 \% \mathrm{ABW}$, $\left.F_{6,84}=2.76, P=0.017\right)$. Pre-planned comparisons between contiguous thrust durations also showed a significantly greater increase in muscle spindle discharge between the 150 and $100 \mathrm{~ms}$ durations at a thrust force of $25 \% \mathrm{ABW}(P=$ $0.03)$. The difference between 100 and $75 \mathrm{~ms}$ durations at $55 \%$ ABW was not statistically significant $(P=0.11)$ but showed the steepest increase in discharge compared to the other contiguous durations. The data suggest that threshold values for thrust duration being able to evoke a significantly large increase in muscle spindle discharge depended upon delivering the HVLA-SM under linear control of force.
3.4. Effect of Specifically Controlling Thrust Displacement versus Thrust Force during Delivery of an HVLA-SM. Similar displacements applied to different spines do not necessarily produce the same force, and vice versa. The relationship between the two is determined by the spine's stiffness. In the present study, where the magnitudes of thrust force or thrust displacement among cats within a cohort were identical, the consequent displacement or force, respectively, could be different within the cohort. The implication for data interpretation is that conclusions based upon the type of thrust control may actually be attributable to either the consequent thrust force or displacement that was not controlled.

To address this possibility, we reorganized the data from the 60 cats in the three displacement cohorts (shown in Figure 3). The reorganization was based upon ranges of thrust force that developed. The ranges were made to encompass magnitudes similar to the thrust force used in the force cohorts. Three groups were formed: $<25 \%$ BW, 30-55\% BW, and $60-85 \%$ BW. Responses from only 56 of the 60 cats fell into the 3 ranges. Thrust forces in the remaining 4 cats fell between $25 \%$ and $30 \%$ BW or between $55 \%$ and $60 \%$ BW. Data from the 56 cats are shown in Figure 6(a). A similar approach was used for the 52 cats in the three force cohorts. The reorganization was based upon the ranges of thrust displacement that developed. The ranges were made to encompass magnitudes similar to the thrust displacement used in the displacement cohorts. Three groups were formed: $1.5-2.5 \mathrm{~mm}$, or $>2.5$ and $<3.5 \mathrm{~mm}$, or $3.5-4.5 \mathrm{~mm}$. Thrust displacements from only 34 of these 52 cats fell into these ranges. Thrust displacements in the remaining 18 cats were either less than $1.5 \mathrm{~mm}$ or greater than $4.5 \mathrm{~mm}$. Data from the 34 cats are shown in Figure 6(b). Under displacement control of the HVLA-SM, spindle responses remained graded with 


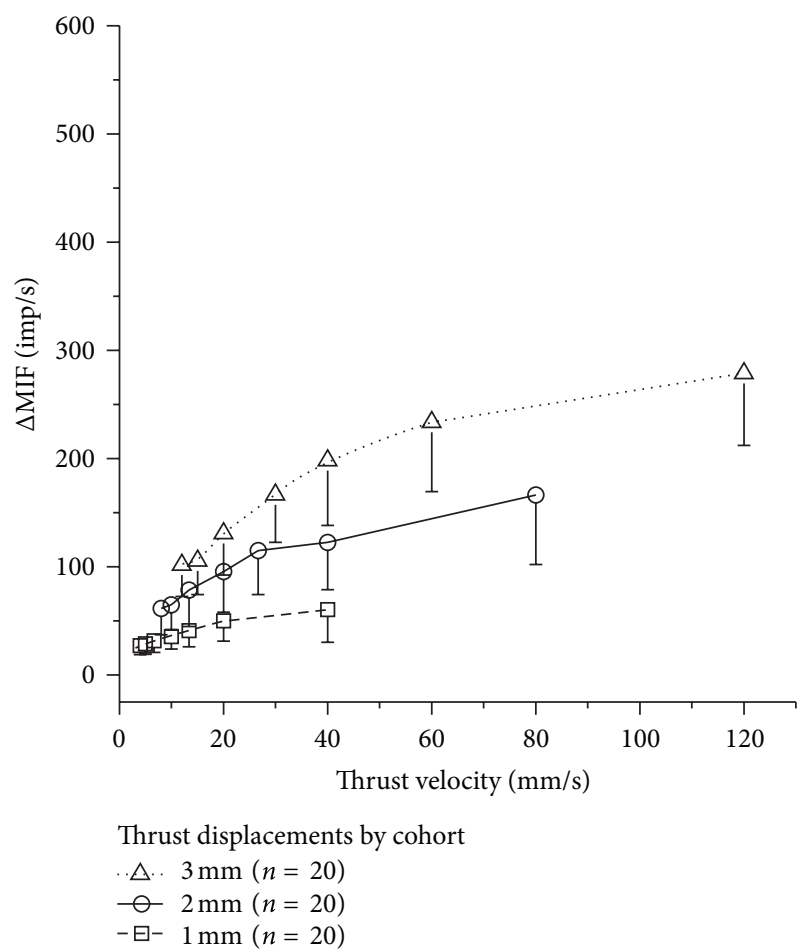

(a)

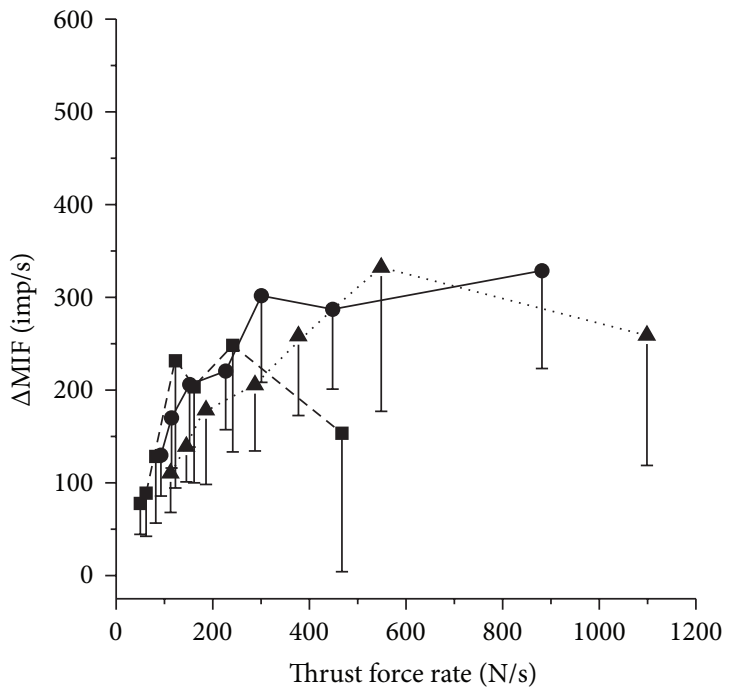

Thrust forces by cohort

... $85 \% \mathrm{BW}(n=20)$

$\rightarrow 55 \% \mathrm{BW}(n=20)$

$-\mathbf{-} 25 \% \mathrm{BW}(n=12)$

(b)

FIGURE 7: Relationship between thrust rate and the average change in mean spindle discharge. (a) Displacement control. (b) Force control. Symbols represent average for the cohort. Error bars represent adjusted 95\% confidence intervals. Abbreviations identical to those in Figure 3.

thrust amplitude regardless of whether the data were grouped according to thrust displacement or thrust force (compare Figure 3 with Figure 6(a)). Under force control of the HVLASM spindle responses were not graded with thrust amplitude regardless of whether the data were grouped according to thrust displacement or thrust force (compare Figure 4 with Figure 6(b)). Thus, the distinct effects of thrust amplitude on the pattern of muscle spindle discharge appeared due to the type of thrust control with which the HVLA-SM was delivered.

3.5. Effect of Thrust Rate. Because displacement and force applied during the thrust phase of the HVLA-SM were made to increase linearly (i.e., at a constant rate), we determined how thrust rate affected the response from the muscle spindles. Figure 7 shows the same data as in Figures 3 and 4 plotted as a function of thrust rate in each cohort. The faster thrust rates reflect the shorter thrust durations. Muscle spindle discharge tended to become maximal as thrust rate increased. This occurred at thrust velocities greater than $20-30 \mathrm{~mm} / \mathrm{s}$ and at thrust force rates greater than $300 \mathrm{~N} / \mathrm{s}$.

\section{Discussion}

In the current study, we undertook an investigation using an established animal preparation as an initial step toward identifying biomechanical characteristics of an HVLA-SM that can help define qualities that contribute to its clinically effective dosage. Identification of these characteristics was accomplished by systematically varying aspects of the HVLASM's amplitude and duration and determining their effects upon changes in neural activity from muscle spindles in the vertebral column. While the mechanism of HVLA-SM's action remains elusive, spinal manipulation's influence on this proprioceptor, the muscle spindle, has long been thought to be an important mediator of its clinical effects [18]. This study revealed several biomechanical characteristics of the short-lever HVLA-SM that would be expected to be particularly influential on neural activity evoked during an HVLA-SM.

First, controlling thrust force and its amplitude affected the pattern of neural activity differently from controlling thrust displacement. A linear increase in thrust force produced similar muscle spindle responses regardless of the peak thrust amplitude (measured as displacement in Figure 4 or force in Figure $7(\mathrm{~b})$ ). On the other hand, a linear increase in thrust displacement produced spindle responses that were graded with the peak thrust amplitude (Figures 3 and 7(a)). In addition, the variability in neural discharge was less when the linear increase in thrust displacement was controlled (compare Figure 3 with Figure 4).

An explanation for these differences may lie in the spine's viscoelastic behavior because the relationship between the forces that develop in the tissues and resulting tissue displacements is nonlinear [36]. Muscle spindles lie in parallel with muscle fibers and are considered physiological length detectors. During the linear increase in thrust displacement, the HVLA-SM likely produced changes in muscle length 
that were linearly proportional and graded with the different magnitudes of thrust displacement. However, when the HVLA-SM's thrust was applied with a linear increase force, paraspinal muscle length would not be expected to increase linearly. The system acted as if the three different magnitudes of applied peak thrust force $(25 \%, 55 \%$, and $85 \%$ BW) could each produce nearly the same change in paraspinal muscle length. This behavior suggests that the thrust of an HVLASM delivered under linear control of force produces a more robust response from muscle spindles because their response depends little on the actual thrust amplitude.

Second, the present study showed that thrust duration and thrust rate are characteristics that affect the magnitude and pattern of proprioceptive input during the HVLASM. Larger changes in spindle discharge occurred as thrust durations became shorter than $150 \mathrm{~ms}$ (Figures 3 and 4). Thrust duration made a particularly large contribution to the neural response when the HVLA-SM was given under force control as evidenced by muscle spindle discharge significantly increasing at thrust durations of 75 to $100 \mathrm{~ms}$ relative to the immediately longer durations (see Figure 4). Faster thrusts under both force and displacement control do not continuously produce larger changes in spindle discharge but instead plateau becoming relatively constant at the three fastest thrust rates (Figures 7(a) and 7(b)). Combined, these temporal aspects of the HVLA-SM indicate the presence of a threshold range of thrust durations and thrust rates that lead to a stable, high frequency neural input from these muscle proprioceptors. We speculate that to be clinically effective, the velocity of an HVLA-SM needs to reach a critical value to engender an appropriate neural response. The presence of such a value or range of values needs to be established with clinical studies.

In treating patients with musculoskeletal complaints, it is not known whether clinicians attempt to control the force or displacement they apply during HVLA-SMs or even if these parameters can be controlled within specific tolerances. From a motor control perspective, the manipulative thrust can be considered a ballistic movement, being short in duration and having a high loading rate. It seems difficult to conceive that clinicians could adjust their motor strategy mid-thrust to change from force to displacement control. Clinicians may learn to control displacement in order to limit spinal movement or patient discomfort because they cannot predict how much resistive force the spinal column will provide. On the other hand, the palpatory procedures typically used to determine the segmental level to manipulate may provide the trained clinician with the ability to anticipate the manipulative force needed and initiate a motor program based upon force control. Efforts have been underway (reviewed in [7]) to understand factors that contribute to the acquisition of spinal manipulation as a motor skill $[37,38]$ while various techniques have been tested to train clinician's to control the biomechanical parameters that characterize a spinal manipulation [39-41].

Although the clinical consequences of muscle spindle activity evoked by a spinal manipulation cannot be determined from the present study, our results may explain a neurophysiological response reported in previous human studies where HVLA-SM causes a short-term reduction in the tibial nerve H-reflex [42-44]. While mobilizations, which are more slowly applied compared to HVLA-SM, have a similar effect, the magnitude of the reduction tends to be less while massage has no effect on the H-reflex $[45,46]$. Reductions in the H-reflex indicate that the muscle spindle's efficacy for increasing alpha-motoneuron excitability has been reduced. It is known that increasing levels of muscle spindle activity reduce the H-reflex [47]. Synaptic, as well as pre- and postsynaptic mechanisms that reduce alphamotoneuron activity, are activated by bursting activity from muscle spindle neurons $[48,49]$. The higher spindle discharge frequencies found in the current study as thrust durations became similar to that used clinically ( $150 \mathrm{~ms}$ [24-26]) may have caused the reported reductions in the H-reflex.

Several aspects of our study may moderate our conclusions regarding the biomechanical parameters of HVLASM that influence muscle spindle responses. Spinal manipulations are typically delivered at a vertebra's end range of motion which distract, gap, and potentially cavitate a facet joint $[4,30,50,51]$. We did not bring the manipulated vertebra $\left(\mathrm{L}_{6}\right)$ to its end range of motion because the magnitude of this movement would have stretched the nerve filament and tore it from the recording electrode. In addition, while nearly all manually delivered HVLA-SMs involve a posteriorto-anterior thrust component, many also involve some degree of vertebral rotation which was not taken into account in this preparation but may be added to future investigations of this nature. Finally, paraspinal tissues are also innervated by low- and high-threshold mechanoreceptors other than muscle spindles that likely respond to spinal manipulation [52]. Whether similar conclusions would arise from these receptors also requires further investigation.

\section{Conclusions}

In conclusion, we have identified several biomechanical characteristics of a lumbar HVLA-SM in an animal preparation that differentially affected the magnitude and pattern of activity from a lumbar muscle proprioceptor. These characteristics include (1) thrust amplitude and whether the peak thrust force or peak thrust displacement is increased linearly; (2) thrust duration; and consequently (3) thrust rate. The range of values which modulated the neurophysiological responses in this study may be different from values in humans. The translational usefulness of this type of animal study is its ability to provide a basis for identifying biomechanical characteristics that could be most relevant to measure and report in clinical efficacy studies of spinal manipulation. This will help the field define and ultimately identify effective dosages of spinal manipulation.

\section{Authors' Contribution}

W.R. Reed and D.-Y. Cao contributed equally to this work.

\section{Acknowledgments}

The authors thank Dean Macken and Steven Struckman at the University of Iowa Design and Prototyping Center for 
the design and construction of the rotary to linear converter and 3-dimensional positioning frame. The authors thank Randall Sozio for technical work and Ying Cao for statistical assistance. This work was supported by NIH Grant NIH U19 AAT004137 to J. G. Pickar and G. N. Kawchuk and conducted in a facility constructed with support from Research Facilities Improvement Grant no. C06 RR15433 from the National Center for Research Resources, NIH.

\section{References}

[1] P. G. Shekelle, A. H. Adams, M. R. Chassin, E. L. Hurwitz, and R. H. Brook, "Spinal manipulation for low-back pain," Annals of Internal Medicine, vol. 117, no. 7, pp. 590-598, 1992.

[2] D. M. Eisenberg, R. B. Davis, S. L. Ettner et al., "Trends in alternative medicine use in the United States, 1990-1997: results of a follow-up national survey," Journal of the American Medical Association, vol. 280, no. 18, pp. 1569-1575, 1998.

[3] M. G. Christensen, D. Kerkhoff, M. W. Kollasch, and L. Cohn, Job Analysis of Chiropractic, National Board of Chiropractic Examiners, Greeley, Colo, USA, 2005.

[4] T. F. Bergmann, "High-velocity low-amplitude manipulative techniques," in Principles and Practice of Chiropractic, S. Haldeman, S. Dagenais, B. Budgell, N. Grunnet-Nilsson, P. D. Hooper, W. C. Meeker et al., Eds., pp. 755-766, McGraw-Hill, New York, NY, USA, 2005.

[5] J. Triano, "The mechanics of spinal manipulation," in Clinical Biomechanics of Spinal Manipulation, W. Herzog, Ed., pp. 92-190, Churchill Livingstone, New York, NY, USA, 2000.

[6] C. Goertz, K. A. Pohlman, R. D. Vining, J. W. Brantingham, and C. R. Long, "Patient-centered outcomes of high-velocity, lowamplitude spinal manipulation for low back pain: a systematic review," Journal of Electromyography and Kinesiology, vol. 22, no. 5, pp. 670-691, 2012.

[7] J. J. Triano, M. Descarreaux, and C. Dugas, "Biomechanics-review of approaches for performance training in spinal manipulation," Journal of Electromyography and Kinesiology, vol. 22, no. 5, pp. 732-739, 2012.

[8] M. Haas, E. Groupp, and D. F. Kraemer, "Dose-response for chiropractic care of chronic low back pain," Spine Journal, vol. 4, no. 5, pp. 574-583, 2004.

[9] M. Haas, E. Groupp, M. Aickin et al., "Dose response for chiropractic care of chronic cervicogenic headache and associated neck pain: a randomized pilot study," Journal of Manipulative and Physiological Therapeutics, vol. 27, no. 9, pp. 547-553, 2004.

[10] J. G. Pickar and Y. M. Kang, "Paraspinal muscle spindle responses to the duration of a spinal manipulation under force control," Journal of Manipulative and Physiological Therapeutics, vol. 29, no. 1, pp. 22-31, 2006.

[11] J. G. Pickar, P. S. Sung, Y. M. Kang, and W. Ge, "Response of lumbar paraspinal muscles spindles is greater to spinal manipulative loading compared with slower loading under length control," Spine Journal, vol. 7, no. 5, pp. 583-595, 2007.

[12] M. Vaillant, T. Edgecombe, C. R. Long, J. G. Pickar, and G. N. Kawchuk, "The effect of duration and amplitude of spinal manipulative therapy on the spinal stiffness," Manual Therapy, vol. 17, no. 6, pp. 577-583, 2012.

[13] C. J. Colloca, T. S. Keller, D. E. Harrison, R. J. Moore, R. Gunzburg, and D. D. Harrison, "Spinal manipulation force and duration affect vertebral movement and neuromuscular responses," Clinical Biomechanics, vol. 21, no. 3, pp. 254-262, 2006.

[14] R. A. Leach, The Chiropractic Theories, Lippincott Williams \& Wilkins, Philadelphia, Pa, USA, 4th edition, 2004.

[15] J. E. Bialosky, M. D. Bishop, D. D. Price, M. E. Robinson, and S. Z. George, "The mechanisms of manual therapy in the treatment of musculoskeletal pain: a comprehensive model," Manual Therapy, vol. 14, no. 5, pp. 531-538, 2009.

[16] J. G. Pickar, "Neurophysiological effects of spinal manipulation," Spine Journal, vol. 2, no. 5, pp. 357-371, 2002.

[17] I. M. Korr, The Neurobiologic Mechanisms in Manipulative Therapy, Plenum Press, New York, NY, USA, 1978.

[18] I. M. Korr, "Proprioceptors and somatic dysfunction," Journal of the American Osteopathic Association, vol. 74, no. 7, pp. 638-650, 1975.

[19] J. G. Pickar, "An in vivo preparation for investigating neural responses to controlled loading of a lumbar vertebra in the anesthetized cat," Journal of Neuroscience Methods, vol. 89, no. 2, pp. 87-96, 1999.

[20] M. C. Brown, I. Engberg, and P. B. Matthews, "The relative sensitivity to vibration of muscle receptors of the cat," Journal of Physiology, vol. 192, no. 3, pp. 773-800, 1967.

[21] J. G. Pickar and J. D. Wheeler, "Response of muscle proprioceptors to spinal manipulative-like loads in the anesthetized cat," Journal of Manipulative and Physiological Therapeutics, vol. 24, no. 1, pp. 2-11, 2001.

[22] M. Vaillant, J. G. Pickar, and G. N. Kawchuk, "Performance and reliability of a variable rate, force/displacement application system," Journal of Manipulative and Physiological Therapeutics, vol. 33, no. 8, pp. 585-593, 2010.

[23] P. S. Bolton and C. T. Holland, "An in vivo method for studying afferent fibre activity from cervical paravertebral tissue during vertebral motion in anaesthetised cats," Journal of Neuroscience Methods, vol. 85, no. 2, pp. 211-218, 1998.

[24] B. W. Hessell, W. Herzog, P. J. W. Conway, and M. C. McEwen, "Experimental measurement of the force exerted during spinal manipulation using the thompson technique," Journal of Manipulative and Physiological Therapeutics, vol. 13, no. 8, pp. 448-453, 1990.

[25] W. Herzog, P. J. Conway, G. N. Kawchuk, Y. Zhang, and E. M. Hasler, "Forces exerted during spinal manipulative therapy," Spine, vol. 18, no. 9, pp. 1206-1212, 1993.

[26] J. J. Triano, "Biomechanics of spinal manipulative therapy," Spine Journal, vol. 1, no. 2, pp. 121-130, 2001.

[27] S. J. Kirstukas and J. A. Backman, "Physician-applied contact pressure and table force response during unilateral thoracic manipulation," Journal of Manipulative and Physiological Therapeutics, vol. 22, no. 5, pp. 269-279, 1999.

[28] K. K. Haussler, C. E. Martin, and A. E. Hill, "Efficacy of spinal manipulation and mobilisation on trunk flexibility and stiffness in horses: a randomised clinical trial," Equine Veterinary Journal, vol. 42, supplement s38, pp. 695-702, 2010.

[29] E. Suter, W. Herzog, P. J. Conway, and Y. T. Zhang, "Reflex response associated with manipulative treatment of the thoracic spine," Journal of the Neuromusculoskeletal System, vol. 2, no. 3, pp. 124-130, 1994.

[30] A. Ianuzzi and P. S. Khalsa, "High loading rate during spinal manipulation produces unique facet joint capsule strain patterns compared with axial rotations," Journal of Manipulative and Physiological Therapeutics, vol. 28, no. 9, pp. 673-687, 2005. 
[31] M. Nathan and T. S. Keller, "Measurement and analysis of the in vivo posteroanterior impulse response of the human thoracolumbar spine: a feasibility study," Journal of Manipulative and Physiological Therapeutics, vol. 17, no. 7, pp. 431-441, 1994.

[32] A. W. Fuhr and D. B. Smith, "Accuracy of piezoelectric accelerometers measuring displacement of a spinal adjusting instrument," Journal of Manipulative and Physiological Therapeutics, vol. 9, no. 1, pp. 15-21, 1986.

[33] D. B. Smith, A. W. Fuhr, and B. P. Davis, "Skin accelerometer displacement and relative bone movement of adjacent vertebrae in response to chiropractic percussion thrusts," Journal of Manipulative and Physiological Therapeutics, vol. 12, no. 1, pp. 26-37, 1989.

[34] G. N. Kawchuk, W. Herzog, and E. M. Hasler, "Forces generated during spinal manipulative therapy of the cervical spine: a pilot study," Journal of Manipulative and Physiological Therapeutics, vol. 15 , no. 5, pp. 275-278, 1992.

[35] C. C. Hunt and D. Ottoson, "Initial burst of primary endings of isolated mammalian muscle spindles," Journal of Neurophysiology, vol. 39, no. 2, pp. 324-330, 1976.

[36] A. A. White and M. M. Panjabi, Clinical Biomechanics of the Spine, J. B. Lippincott, Philadelphia, Pa, USA, 2nd edition, 1990.

[37] J. J. Triano, C. M. Rogers, S. Combs, D. Potts, and K. Sorrels, "Developing skilled performance of lumbar spine manipulation," Journal of Manipulative and Physiological Therapeutics, vol. 25, no. 6, pp. 353-361, 2002.

[38] J. J. Triano, J. Bougie, C. Rogers et al., "Procedural skills in spinal manipulation: do prerequisites matter?" Spine Journal, vol. 4, no. 5, pp. 557-563, 2004.

[39] M. Descarreaux, C. Dugas, K. Lalanne, M. Vincellete, and M. C. Normand, "Learning spinal manipulation: the importance of augmented feedback relating to various kinetic parameters," Spine Journal, vol. 6, no. 2, pp. 138-145, 2006.

[40] J. G. Scaringe, D. Chen, and D. Ross, “The effects of augmented sensory feedback precision on the acquisition and retention of a simulated chiropractic task," Journal of Manipulative and Physiological Therapeutics, vol. 25, no. 1, pp. 34-41, 2002.

[41] J. J. Triano, C. M. Rogers, S. Combs, D. Potts, and K. Sorrels, "Quantitative feedback versus standard training for cervical and thoracic manipulation," Journal of Manipulative and Physiological Therapeutics, vol. 26, no. 3, pp. 131-138, 2003.

[42] B. A. Murphy, N. J. Dawson, and J. R. Slack, "Sacroiliac joint manipulation decreases the H-reflex," Electromyography and Clinical Neurophysiology, vol. 35, no. 2, pp. 87-94, 1995.

[43] N. Orakifar, F. Kamali, S. Pirouzi, and F. Jamshidi, "Sacroiliac joint manipulation attenuates alpha-motoneuron activity in healthy women: a quasi-experimental study," Archives of Physical Medicine and Rehabilitation, vol. 93, no. 1, pp. 56-61, 2012.

[44] J. D. Dishman and R. Bulbulian, "Spinal reflex attenuation associated with spinal manipulation," Spine, vol. 25, no. 19, pp. 2519-2525, 2000.

[45] J. D. Dishman and R. Bulbulian, "Comparison of effects of spinal manipulation and massage on motoneuron excitability," Electromyography and Clinical Neurophysiology, vol. 41, no. 2, pp. 97-106, 2001.

[46] J. D. Dishman and J. Burke, "Spinal reflex excitability changes after cervical and lumbar spinal manipulation: a comparative study," Spine Journal, vol. 3, no. 3, pp. 204-212, 2003.
[47] S. A. Wood, J. E. Gregory, and U. Proske, "The influence of muscle spindle discharge on the human $\mathrm{H}$ reflex and the monosynaptic reflex in the cat," Journal of Physiology, vol. 497, no. 1, pp. 279-290, 1996.

[48] L. M. Mendell, "Ia fiber architeture: implications for the functional role of presynaptic inhibition," in Presynaptic Inhibition and Neural Control, P. Rudomin, R. Romo, and L. M. Mendell, Eds., pp. 259-270, Oxford University Press, New York, NY, USA, 1998.

[49] H. Hultborn and J. B. Nielsen, "Modulation of transmitter release from Ia afferents by their preceding activity-a "postactivation depression," in Presynaptic Inhibition and Neural Control, P. Rudomin, R. Romo, and L. M. Mendell, Eds., pp. 178-191, Oxford University Press, New York, NY, USA, 1998.

[50] P. E. Greenman, Principles of Manual Medicine, Williams \& Wilkins, Baltimore, Md, USA, 1989.

[51] G. D. Cramer, N. R. Tuck, J. T. Knudsen et al., "Effects of sideposture positioning and side-posture adjusting on the lumbar zygapophysial joints as evaluated by magnetic resonance imaging: a before and after study with randomization," Journal of Manipulative and Physiological Therapeutics, vol. 23, no. 6, pp. 380-394, 2000.

[52] R. G. Gillette, "A speculative argument for the coactivation of diverse somatic receptor populations by forceful chiropractic adjustments," Manual Medicine, vol. 3, no. 1, pp. 1-14, 1987. 


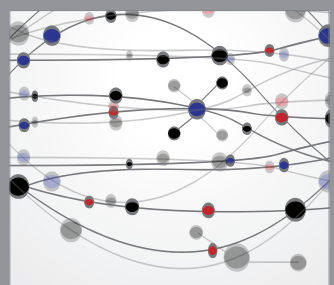

The Scientific World Journal
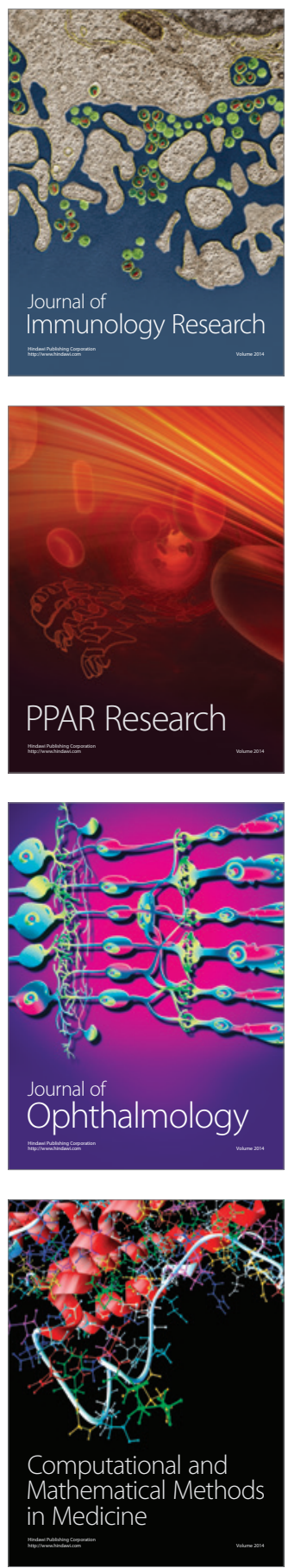

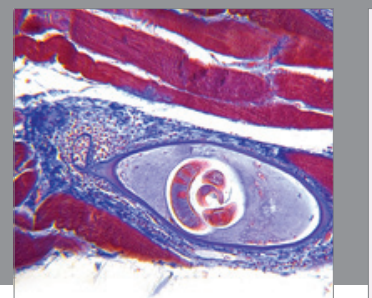

Gastroenterology

Research and Practice
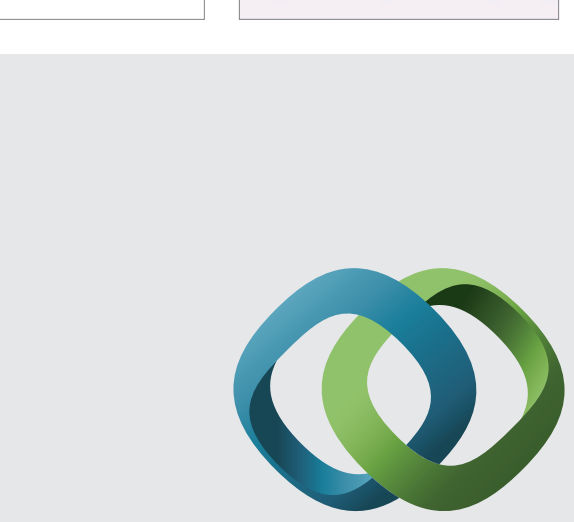

\section{Hindawi}

Submit your manuscripts at

http://www.hindawi.com
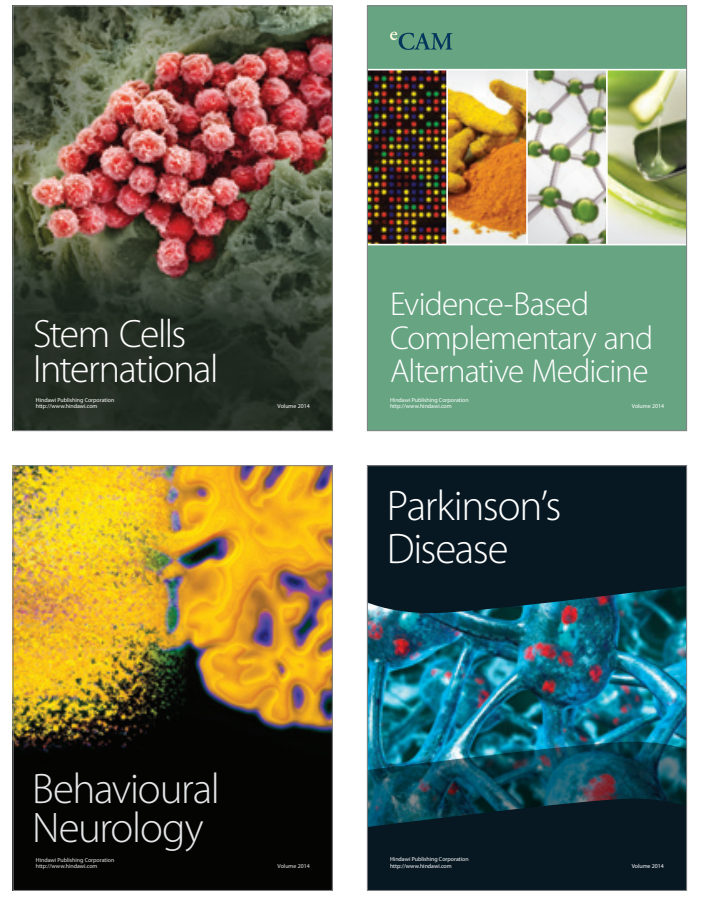
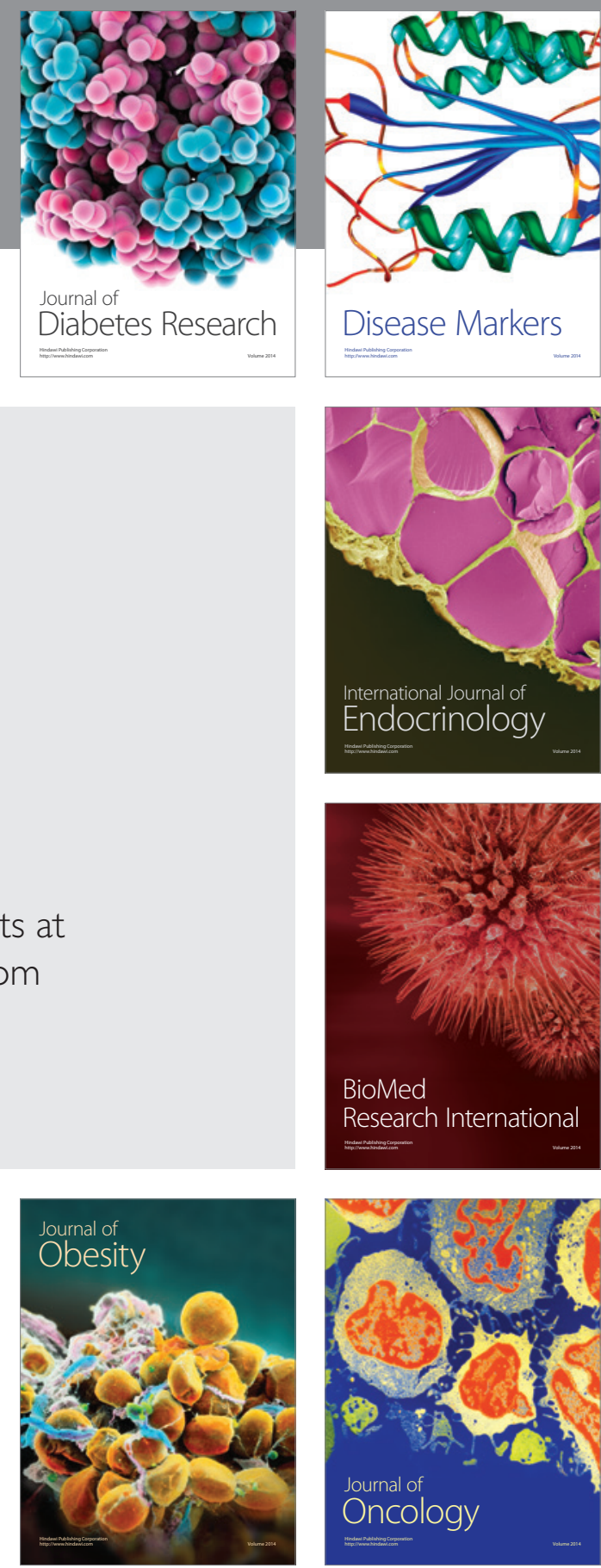

Disease Markers
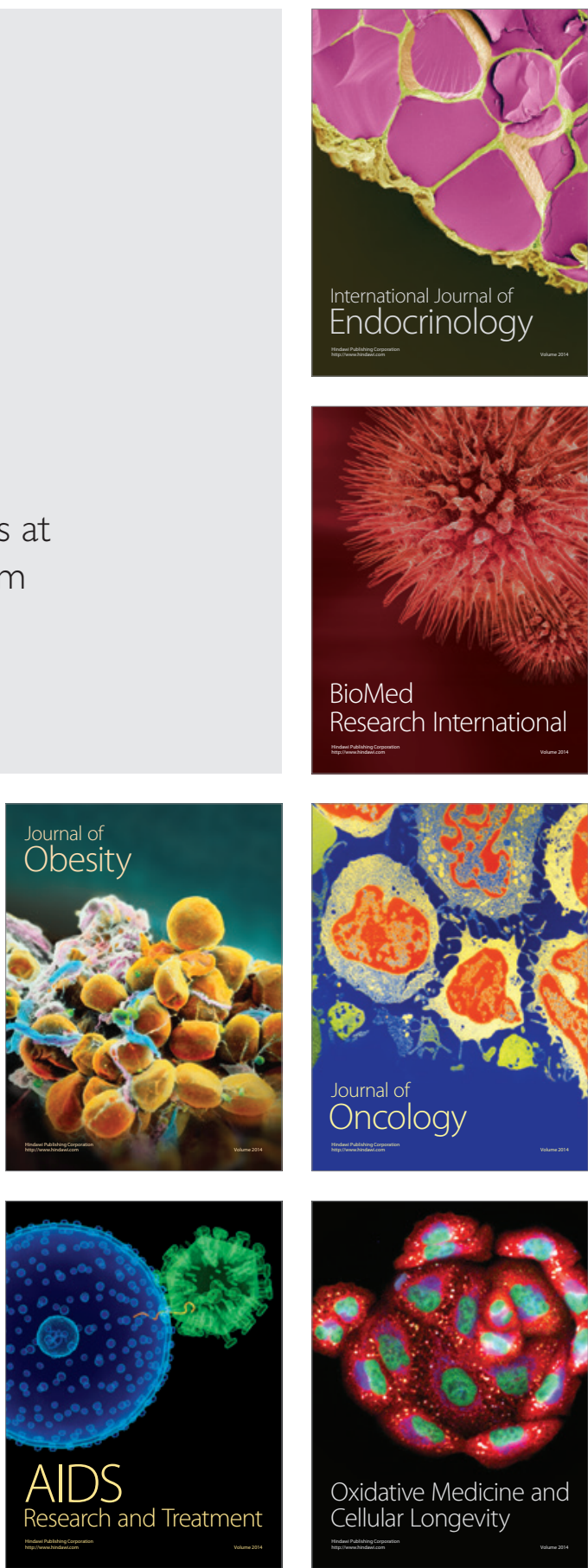